\title{
The Reconsideration of Chinese Automotive Design Based on Traditional Thoughts of Creative Works
}

\author{
Zhenjian $\mathbf{L i}^{*}$, a, Tianyuan $\mathbf{F u}^{\mathrm{b}}$ \\ Hongik University, Seoul, Korea, 04066 \\ Hebei University of Science and Technology, Shijiazhuang, China, 050018 \\ ${ }^{a} e$-mail:leezonejian@126.com, ${ }^{b} e$-mail:leezonejian@naver.com
}

Keywords: thoughts of creative works; traditional implements; Chinese elements; automobile design

Abstract: With the fast development of Chinese automobile industry, Chinese localization design still stays at the level of transforming element symbol into application. The question is how to present the Chinese characteristics and Chinese flavor of Chinese localization design from inside to outside. This article is based on Chinese traditional implements, searching for the connection of culture implication behind the shaping of Chinese traditional implements. The analysis of the culture limitation of social formation and mainstream thoughts; thoughts of creative works (design); aesthetic style of age and comprehension of human beings behind traditional implements aims to learn from essence of ancient outstanding thoughts of creative works. Chinese localization design gains enlightenment from the analysis, which draws a discussion that in which way could Chinese localization design present the Chinese characteristics and connotation rather than formalization of Chinese elements. The heritage of Chinese localization design of modern automobile is combined with practical cases of applying and discovering the essence of traditional of creative works in design.

Chinese have realized the dream of manufacturing automobiles from the birth of the first car "Jie Fang" truck to the birth of "Dong Feng" car and "Hong Qi" car since new China was founded. Foreign brand automobiles have entered into China since the beginning of reform and opening-up policies were launched. Foreign enterprises cooperated with local enterprises to establish joint ventures. Since then, car manufacturers in China have entered into the stage of integrated development. To some extent, it is an important watershed of domestic car development. China has taken world's first place of Japan until 2009, which is worthy of becoming a big country of automobile. At present, the output of domestic automobiles has break through 10 million. According to the data of China Association of Automobile Manufacturers, the sales of automobiles in China exceeded 28 million in 2016, which kept the first place for consecutive 8 years. Car industry in China has made a large progress with high-speed development. However, due to the lack of own brand, the expression of exchanging market for technical mode has been lasted in a long time. In addition, compared to international standard, there is a large gap between the research and development capacity. Especially, the main core technology depend too much on foreign automobile enterprises, this is the reason why designers from China own less speaking right during 
the process of front end design to the middle and final stages of development. Foreign designers mainly guide the car design in China. Under such environment, China's own car brands came into being in the market. For example, Geely set up in 1986, BYD established in 1995 and Chery in 1997. These domestic automobile enterprises began to explore the way of China's own brands. Originally, national enterprises were lacking in the experience of car design. Many vehicle models were copied from foreign car design as others were improved on account of foreign cars. Where is the way of car design in China? World famous automotive designer, Giorgetto Giugiaro put forward that car design in China are lacking in Chinese elements on basis of design style. Automobile enterprises in China started to promote the image of local car design in order to stop imitating foreign car design at an early date. The application of Chinese elements had been constantly tried in the fields of car design since the concept of 'Chinese elements' presented in 2004. Particularly, after China succeeded in bidding Olympic Games, large amounts of Chinese element were used in car design.

In the end of 1965, limousines 'Hong Qi CA770' were manufactured by China FAW Group Corporation. The Chinese elements of fans, clouds and palace lantern were applied into the car design. Palace lantern is one of the tradition handicrafts which own characteristics of Chinese folks. Except the function of lighting, the diversity patterns on the cover on behalf of message of rich and extravagant, which make the design of 'Hong Qi CA770' contain high conciseness of Chinese traditional elements and culture of good luck. Besides, the body of car has a pushing trend with a steady state while the lines are seized from furniture in Ming and Qing dynasty. With the help of these 'Chinese elements', the national spirit of progress and proud humility are conveyed to the world.During the period of Beijing Olympic Games, there was a design trend of 'Chinese style' among the whole country. Geely published vehicle model of panda in 2008, which is derived from pandas. Their lovely images leave deep impression on people. Otherwise, they own unique features of eyes, head and hair with white and black color. Pandas are the messengers of peace and friendship.Because of the special meaning of pandas, Geely applied the simulation of pandas into car design. The front face of the car is in big mouth type while the headlights of the car are seemed like the dark circle of pandas'. The black front air-inlet grille with white car body seizes the features of panda. Meanwhile, the whole vehicle model design is fruity and small, which gives people impression of lovely and clever.

Hong Qi published LS5 (high-end SUV model) on Shanghai auto show in 2015. The trim strips of front air-inlet grille are printed patterns of dragon. The middle gridding design is applied the modeling of Chinese traditional windows. The taillights and wheel hubs adopts the elements of clouds such as the picture of 'two dragons play golden sunflower'. All of these elements reflect that designers extract Chinese elements from traditional implements and patterns. This is the demonstration of the positive exploration of local car design. On the other hand, LS5 presents the imitation of Range Rover, which exposes the weak car design in China. How to apply Chinese elements into local car design still has a long way to explore, which couldn't be achieved in a short time.At the same time, in 2015 Shanghai auto show, Chery put forward the concept car $\alpha 5$, which extracted the design elements of bridge and roof of ancient constructions. This kind of bridge owns roof and it supplies people with a shelter where they could communicate with each other.Chery $\alpha 5$ applies the features on middle gridding, which make air-inlet grille and front headlights as a whole and give people a natural feeling. The 'dot matrix' design of middle gridding is originated from the concept of 'Ying Yang'. Chery 'Bo Yue' was published in 2016 which owned same design method as the former. The model of instrument in the car is derived from the bridge on West Lake in Hangzhou. The pattern of control board is seized from terraced fields, which give people a comfortable feeling. The feature lines captured from the beautiful jade are applied on the trim strips, which leaves a associative perception on people. These two kinds of cars have made a large 
progress in local car design, which is a positive expression of Chinese car design as well.

As is known to all, large amounts of Chinese elements are applied on car design of these local car brands. The abstract shape captured from Chinese traditional implements, the simulation of pandas and feature lines seized from the traditional constructions are three methods used in car design. The design of China mentioned in international and culture connotations have to be added in Chinese elements, which need to find answers in history. Chinese culture just exist in history seemed to become a mindset that China design could not get rid of the constraint of history and only Chinese elements are used could manifest the concept of local design. It is not only the misunderstanding of local car design, but also narrow comprehension of national culture.Therefore, the first aim of local car design has to focus on what is the essence of design? The essence of design is purposeful creation. ${ }^{[1]}$ Nevertheless, the aim of present car design is to apply appropriate design methods. Except expressing the features of Chinese traditional and modern culture, habits and requirements have to be integrated. The spread of Chinese culture has to bear the weight of design methods with externalization. The modern car design in China still apply Chinese elements to convey physical form of Chinese culture, which neglects the influence of social thoughts and forms to modeling. The unique situation of traditional excellent handicrafts is the result of social thoughts such as the bronze ware of Xia dynasty, Shang dynasty and Zhou dynasty. All of these implements developed from eating utensils to sacrifice implements. The modeling of bronze ware kept the same pace the society. Bronze wares became the carrier of thoughts, science and culture and system in that time, which is an objective reflection of the social culture. To a large extent, the construction methods of China gardens could reflect the design thoughts of Taoist school, which focus on the balance of people and nature. The modeling of mountains has to be ordered to express the feeling of deep, peace, hotness, cold and other kinds of prospects. This is the fundamental principal of Chinese traditional gardening arts which combines the design method and basic standard. ${ }^{[2]}$

Nowadays, these are China design. Though the modeling is not the same and the diversity expression of Chinese elements owns a large difference, all of them present the temperament of China. They could be called 'Good Design' which reflects the characteristics and cultural connotation.Good design could be understood from three lays, 'Looks Good; Works Well; Feel Great'. ${ }^{[3]}$

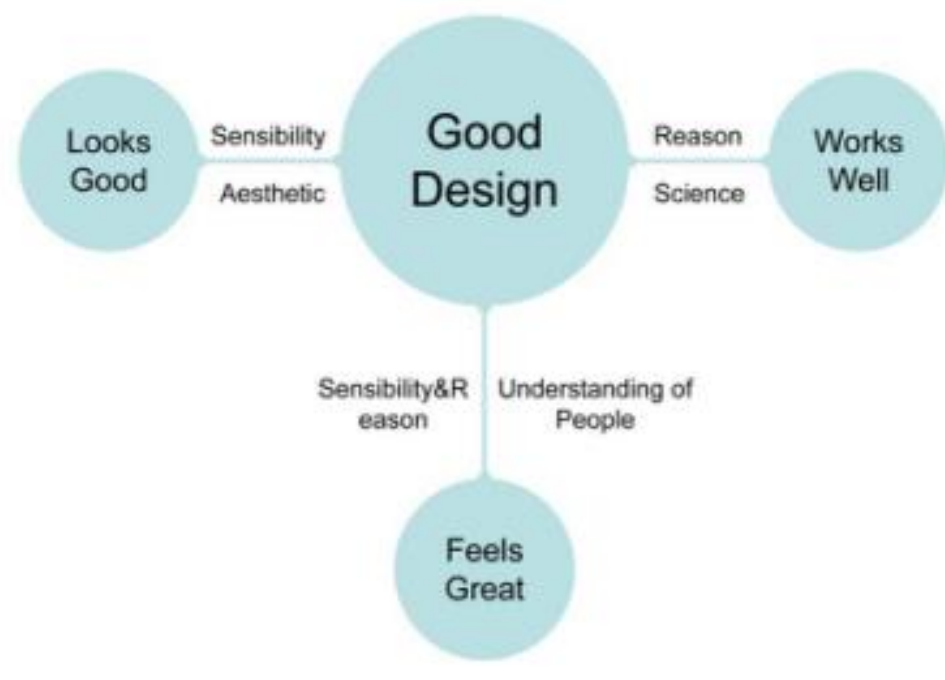

Fig.1 Three levels of good design 


\section{Good Looks: Aesthetics and Sensibility}

At first, good looks mean aesthetic and sensibility. There is big different in aesthetics between ancient China to modern China. For example, the trend of in Weijin dynasty had great impact on filed of arts and design. While the description of seven sages of the bamboo grove in 'Jinshu' incisively and vividly showed the typical features of 'Show clear phase bone', it became the aesthetic characteristics as well. In 1983, the dish pot dig from Nanjing was produced in the period of three kingdoms. The body of the pot is a very large circle. To the period of Southern dynasties, the neck of pots became higher and the body turned into slim. The whole model converted into the style of slim and high, which left people a feeling of dignified and beautiful and perfectly fit the trend of 'Show clear phase bone'.

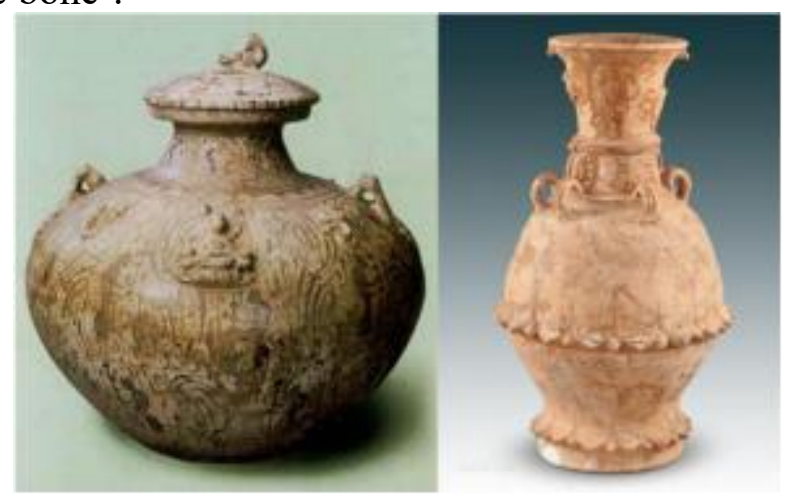

Fig.2 The mldelling changes of celadon

The increase of lotus pattern and grass pattern were popular among that time, which was influenced by the widely spread of Buddhist thought as the reflection of culture restriction. There was a large distance between different ancient dynasties. Each dynasty would appear relative social standard on basis of different culture habits. For instance, red signal lamp of car is used to represent 'stopping', this is the reason why the lamp located in the tail of the car. Green signal lamp of car represents 'passing' and yellow signal lamp of car represents 'warning'. Therefore, the design of implements is constrained by the aesthetics of the time and the impact of social mainstream thoughts and culture. Local car design should not only focus on the aesthetics and aesthetic trend, but also keep pace with the domestic social mainstream thoughts and culture. Otherwise, local car design should to design under the societal framework, which could fit the culture behavior standard and knowledge structure of Chinese rather than pile up Chinese elements on modern car design.

\section{Works well: Science and Reason}

Secondly, 'works well' means science and Reason. In ancient China, there was an exploration and recognition to the relationship of 'sky', 'ground' and 'people'. Through the combination of history, which formed viewpoint of 'three types of talent'at last. It was put forward systematically in Shang Zhou dynasty, which expressed in the design and model thoughts. Book of Diverse Crafts called 'sky owns time, ground owns air, material own beauty, crafts own skill'. ${ }^{[4]}$ This is not only the reflection of the command and application to natural environment and natural law, but also the confirmation to 'science' through the command and application to objective law. 'Sky owns time' means seeking natural law during the process of design and modeling. 'Ground owns air' means that people in ancient China had a clear comprehension of different regions, different natural environments and different raw materials. To modern car design in China, the difference between south and north should also be considered such as natural environments, the characteristics of city traffic and application of typical local raw materials. This not only shows that people owned a full 
knowledge of quality and characteristics of material, but also they had much experience to material aesthetics. 'Crafts own skill' means that the requirement of 'skill' could be achieved by means of elaborately process. On basis of 'material own beauty', good implements could be manufactured. It can be showed that car design in China should get breakthrough both in modeling and functions. China's own characteristics should be highlight such as region, environment, material and crafts.

\section{Feel great: Understanding of people and Sensibility and Reason}

At last, 'feels great' signifies the understanding of human beings and sensibility and rationality. Neo-Confucianism rose in Song dynasty provided ideological guarantee for the development of science. Three of the four great inventions, compass, typography and powder were invented at that time, which showed that Neo-Confucianism played a key role in accelerating the development of science and technology. After the scientific practice permeated producing activity. Artisans accepted the idea of laying emphasis on wooden machinery in order to improve the instrument of production and liberate labor force. Wang Zhen explained the relationship between human beings and instruments clearly in 'Nongshu'. 'People are the foundation of materials while materials are used because of human beings', which lays emphasis on the consideration of human beings. Remarkably, although German automobiles own many brands, each brand has its unique modeling. Whereas, knob switches are widely applied in interior design, which is aimed to assist people to precisely control the operation mode. Furthermore, knob switch is used to rotate, panel is used to push, narrow and long square hole is used to insert. Customers could know how to manipulate the implements through reasonable setting in advance. Besides, accurate information and visualization of function could be conveyed to customers. Without the assistance of pictures, signs and explanation, the matching of manipulation intention and actual operation could be accurately expressed. The relationship among customers' intention, operating steps and operating results should be more specific and explicit. ${ }^{[5]}$ It reflects the national characteristics of Germans as sensibility and preciseness. Automobile brands in Japan pay more attention the detailing of cars. Both of the interior design and exterior design are deeply controlled, which originated from the comprehension of fine and smooth characteristics. Modern China car design should show respect to the life source of modern Chinese, which fit for the value orientation of modern Chinese as well. Experience the life habits of modern Chinese, meet the actual needs of modern Chinese and fully understand of people would designers make better cars with consideration of people. The precious wealth accumulated in the long history of China is the pride of modern Chinese designers. The vitality of culture is to develop constantly. Let Chinese traditional culture get rid of history and derive the design thoughts from the history.

As it known to all, national economy has kept a high speed development since the reform and opening-up policy carried out 40 years ago. Chinese confront the future actively and confidently. As the Chinese automotive designers, only could they design real localized cars by understanding the social formation and mainstream thoughts of society, perceiving the aesthetics of modern Chinese, discovering the characteristics of different regions and judging the requirements and essence of human beings. All of the above could make China's own car brands have their own position around the world.

\section{References}

[1] Wei Lai. Design Code [M]. Beijing: China CITIC Press, 2010.

[2] Wang Li. A Brief History of The Development of Chinese Design thinking [M].Changsha: Hunan Science \& Technology Press, 2003.

[3] [Korea] Ken Nah. How to think about design: Cultivate awareness of design innovation [M]: Guo Shuhui, Trans. 
Beijing: Publishing House of Electronics Industry, 2011.

[4] [Qing] Sun Zhirang. Justice of the Zhou Dynasty [M]. Beijing: ZhongHua Book Company Press, 1987; Volume74.

[5] Norman, Donald A. The Design of Everyday things [M].New York: Basic Books Press, 2013.

[6] Chang Bing. Car design and Chinese elements [J]. Auto Business Review, 2007(10); PP.36.

[7] Li Yanzu. 'material own beauty, crafts own skill': Design Thinking 〈Zhou Li·Dong Guan·Kao Gong> [J]. Journal of Nanjing Arts Institute (Fine Arts \& Design), 2010(5); PP.78-81. 